\title{
O USO DE PATENTES COMO FONTE DE INFORMAÇÃO EM DISSERTAÇÕES E TESES DE ENGENHARIA QUÍMICA: O CASO DA UNICAMP
}

\author{
Juliana de Paula Ravaschio \\ Leandro Innocentini Lopes de Faria \\ Luc Quoniam
}

\section{Resumo:}

Acredita-se que as patentes são pouco exploradas como documentos fornecedores de informações; tanto por empresas, quanto por instituições de pesquisa, universidades, etc. Nesse contexto, o presente artigo teve a finalidade de investigar se os documentos de patentes são utilizados como fonte de informação nos trabalhos acadêmicos (dissertações de mestrado e teses de doutorado). Para isso, foram selecionados trabalhos da área da engenharia química, do período de 2000 a 2007, da Universidade Estadual de Campinas (UNICAMP). Os dados foram coletados através das patentes citadas e referenciadas nos trabalhos acadêmicos e a amostra utilizada foi de 586 trabalhos. Os resultados dessa pesquisa evidenciaram que $16,4 \%$ dos trabalhos analisados utilizaram patentes como fontes de informação e citaram esse tipo de documento. Além disso, este trabalho indicou que as patentes americanas são as mais citadas por trabalhos da UNICAMP (63,8\%). Porcentagens menores ficaram para as patentes japonesas $(9,0 \%)$, patentes européias $(7,2 \%)$, patentes inglesas $(4,0 \%)$, patentes alemãs $(3,2 \%)$ e patentes brasileiras $(2,7 \%)$.

\section{Palavras-chave:}

Patentes; Informação tecnológica; Pesquisas acadêmicas; Fontes de informação

\section{THE USE OF PATENTS AS INFORMATION SOURCE IN CHEMICAL ENGINEERING DISSERTATIONS AND THESES: THE CASE OF UNICAMP}

\begin{abstract}
:
It is believed that patents are not fully explored as information providers documents, both by companies and by research institutions or universities. In this context, this paper aimed to investigate whether patents are used as information sources in academic works (master's dissertations and doctoral theses). For this, works of chemical engineering from 2000 to 2007 of the State University of Campinas, Brazil (UNICAMP) were selected. Data were collected through the patents cited and referenced in academic works and the sample comprised 586 items. The results of this study have demonstrated that $16.4 \%$ of the works analyzed have used patents as information sources and have also cited this kind of document. In addition, results indicated that U.S. patents are the most cited by researchers from UNICAMP (63,8\%). Lower percentages were observed for Japanese patents $(9,0 \%)$, European patents (7,2\%), English patents (4,0\%), German patents (3,2\%) and Brazilian patents $(2,7 \%)$.
\end{abstract}

\section{Keywords:}

Patents; Technological information; Academic research; Information sources 


\section{INTRODUÇÃO}

Há tempos que a humanidade vive um processo de modificações e rupturas aonde o conhecimento, a educação e a informação possuem papel significativo neste processo de transição. O desenvolvimento tecnológico está cada vez mais apoiado nas inovações.

É de grande valia recordar então, a visão teórica sobre a economia capitalista de Joseph Shumpeter; um dos pensadores mais importantes no estudo dos fenômenos econômicos. Shumpeter sempre defendeu que os "fenômenos econômicos não podem ser explicados com base na teoria neoclássica, a qual considera a tecnologia como uma variável exógena ao processo de desenvolvimento econômico”. (TAVARES, KRETZER e MEDEIROS, 2005, p.1).

Para Schumpeter (1982) as mudanças econômicas são resultados das interações e/ou impactos das inovações tecnológicas no sistema econômico. Isso significa que a tecnologia passou a ser considerada uma variável endógena ao processo de desenvolvimento econômico e sem sombras de dúvidas, assume cada vez mais um crescente e importante papel na estrutura econômica determinante.

Na ampla questão da inovação tecnológica, destaca-se o tema propriedade intelectual e, mais especificamente, a questão das patentes. Quando se trata do assunto inovação tecnológica, logo vem à mente o registro de patentes, cujo número de registros no Brasil ainda é muito pequeno quando comparado a outros países; principalmente países desenvolvidos como Estados Unidos.

No cenário brasileiro, a Universidade Estadual de Campinas (Unicamp), ocupa o $1^{\circ}$ lugar dentre as demais instituições de ensino e pesquisa, no número de patentes junto ao Instituto Nacional de Propriedade Intelectual (INPI). (BOUND, 2008; ALBUQUERQUE, 2003). Já que a questão da propriedade intelectual, ou melhor; das patentes é algo tão presente na realidade da Unicamp, fica a dúvida se a mesma é vista como fonte de informação tecnológica em pesquisas no âmbito acadêmico, mais especificamente nas dissertações de mestrado e teses de doutorado.

Essa dúvida deve ser sanada ao final desse trabalho, que tem por objetivo verificar se alunos da área da engenharia química da Unicamp citam patentes em seus trabalhos 
acadêmicos. Este presente artigo é parte de um estudo para uma dissertação de mestrado que procura verificar o uso das patentes em trabalhos acadêmicos de engenharia.

Percebe-se uma carência de estudos que discorram sobre o uso da informação patentária no âmbito acadêmico. O que muito se encontra, retrata o uso das mesmas por empresas visando o monitoramento tecnológico de concorrentes, prospecção tecnológica ou a importância das informações contidas num documento de patente. Mas a própria literatura indica que as informações de patentes não são utilizadas como deveriam.

\subsection{Patentes: conceitos e uso como fonte de informação}

Na tentativa de compreender melhor o assunto, é necessário utilizar as fontes existentes que tratam da patente como um documento que traz ricas informações para a pesquisa e outros fins, e que discorram sobre as vantagens de se utilizar informação patentária, as possíveis facilidades ou dificuldades para o seu uso, enfim; todas as informações acerca do tema, assim como a opinião dos autores que tratam desse assunto.

De acordo com o Instituto Nacional de Propriedade Industrial ${ }^{1}$ (2005 apud FERRAZ, 2006, p.16), por “documento de patente entende-se tanto o pedido de patente publicado, pendente ainda da concessão, como a patente em vigor ou patente extinta”.

No Brasil, a patente tem validade de vinte anos de proteção e depois disso, cai em domínio público podendo ser utilizada por toda a sociedade. Macedo e Barbosa (2000) lembram que a matéria técnica protegida pela patente é divulgada ao público pela publicação do pedido que é feita até dezoito meses após o depósito do pedido no país ou da prioridade mais antiga. Desta forma, a tecnologia que se requereu a proteção, não fica sendo um mero monopólio do inventor, mas também, uma fonte de informação tecnológica; ofertando à sociedade um novo conhecimento técnico que facilita a geração de novas invenções. Na verdade, o direito de monopólio é restrito à produção de mercadorias e, dessa forma, o conhecimento técnico protegido pela patente pode ser livremente utilizado para pesquisa e desenvolvimento de novas invenções ou para aperfeiçoamentos; também considerados invenções.

\footnotetext{
${ }^{1}$ INSTITUTO NACIONAL DE PROPRIEDADE INDUSTRIAL. Patentes. Disponível em: <http://www.inpi.gov.br>. Acesso em: 16 nov. 2005.
}

(c) Revista Digital de Biblioteconomia e Ciência da Informação,Campinas, v.7, n. 2, p. 219-232, jan./jun. 2010- ISSN: 1678-765X. 
Ainda de acordo com Macedo e Barbosa (2000), a informação patentária tem grande utilidade para usuários concentrados principalmente nas empresas, instituições de pesquisa e desenvolvimento $(\mathrm{P} \& \mathrm{D})$, universidades, autoridades governamentais, agentes de propriedade industrial, inventores isolados, estudantes de engenharia e cursos técnicos. Barroso, Quoniam e Pacheco (2009) também reforçam a importância da patente para as pessoas que trabalham com pesquisa e desenvolvimento; já que é necessário conhecer o estado da arte de uma tecnologia para não acontecer do pesquisador perder tempo “reinventando a roda”.

Mas sabe-se que quando pesquisadores ou cientistas desenvolvem um produto ou uma tecnologia, geralmente procuram informações sobre o estado da técnica nas fontes clássicas de informação como: anais de congressos, artigos de periódicos, ou contato com colegas e assim, passam por alto no conteúdo de documentos de patentes por consideralas mais como um instrumento comercial do que uma fonte de informação. (SCHWANDER, 2004)

Com essa atitude, esses profissionais perdem uma valiosa fonte de conhecimento já que as patentes não só oferecem um panorama das tecnologias já existentes, mas também apontam informações sobre o titular de uma tecnologia, assim como os principais agentes que atuam em determinado setor.

Há mais de duas décadas atrás, Araújo (1981) já concluía que a patente, de maneira geral, era vista tão somente como proteção legal à propriedade industrial e como incentivo à capacidade criadora e ao espírito inovador no campo da técnica. A autora já indicava que a patente exercia uma função muito mais ampla, constituindo um instrumento através do qual o conhecimento tecnológico deixa de ser segredo para assumir o papel de bem econômico.

Araújo (1981) considerava que naquela época, a utilização da patente como fonte de informação ainda era limitada. Seus usuários eram grupos fechados de especialistas e de profissionais de patentes.

Mais de uma década depois, pode-se perceber que a patente ainda continua com seu uso limitado. De acordo com Walker (1995), os pesquisadores preferem registrar suas descobertas, se comunicar com seus pares e utilizar as informações dos periódicos 
científicos ao invés das patentes. Estabelecendo uma comparação dos periódicos com as patentes, o autor aponta que grande parte das informações que estão no documento de patente não são publicados em outro lugar e isso inclui o periódico científico.

É possível perceber a importância enfatizada por alguns autores sobre a informação contida num documento de patente. Além de ser de grande valia para pesquisadores ou para agentes de propriedade industrial, é possível utilizar as informações das patentes para outros fins e para outros profissionais, como por exemplo: agências governamentais de planejamento e formulação de política, para a administração de empresas, para a divisão de marketing, de licenciamento e negociação de tecnologia, entre outros.

França (1997) concorda com os outros autores quando coloca que o documento de patente deveria ser a mais importante fonte primária de informação tecnológica, mas reconhece que raramente a patente é levada em consideração, quer pelo usuário tecnologista ou engenheiro, quer pelo profissional da informação, no momento da recuperação de informações técnicas.

Em seu trabalho, França (1997) aponta algumas restrições observadas para justificar o pouco uso de informações patentárias por esses profissionais comentados acima. O autor acredita que pesquisadores e bibliotecários desconhecem o tipo de informação encontrada num documento de patentes, já que os cursos de $2^{\circ}$ e $3^{\circ}$ graus não contemplam o aprendizado desta matéria. Soma-se a isso, a dificuldade de se interpretar as informações contidas nas patentes. Além disso, a publicação da patente ainda não indica a concessão da patente; o que pode ser uma invenção de sucesso duvidoso. Por último, o autor observa que os pesquisadores acreditam que as informações contidas nas patentes serão levadas ao seu conhecimento por outros meios. Por exemplo o periódico científico.

Em relação à última observação, Oliveira e Suster (2005) apontam que as patentes apresentam vantagens se comparadas à outras fontes de informação principalmente por ser um documento que divulga a informação mais rapidamente do que as outras fontes, já que na maioria dos países os documentos são publicados antes da sua concessão, como já foi mencionado por Macedo e Barbosa (2000). 
No Brasil, o debate acerca da importância das atividades de pesquisa científica e tecnológica tem se concentrado principalmente no ambiente acadêmico. Grande parte da atividade de pesquisa e desenvolvimento do país ocorre em instituições governamentais e outros centros acadêmicos, com uma participação ainda pequena por parte do setor produtivo. Desta forma, Oliveira (2005, p.S40) considera de extrema importância a “ampla divulgação não só das informações de patentes nesses âmbitos, mas também o estímulo à pesquisa bibliográfica em banco de patentes por alunos de cursos tecnológicos de graduação e pós-graduação”. Assim, seria possível acompanhar a velocidade de desenvolvimento de novas tecnologias, já que o volume aproximado de novos pedidos de patentes é de 600 mil por ano.

Com a informática e a internet, a possibilidade de consulta a banco de patentes no mundo tornaram-se muito mais acessíveis. Praticamente todos os escritórios de patentes do mundo disponibilizam suas coleções na internet para consultas públicas, além de páginas de várias empresas especializadas em busca e prospecção tecnológica.

Mesmo com essas facilidades existentes nos dias de hoje, Garcia (2006) conclui que "no âmbito Brasil, a patente não atua como fonte de informação, embora seja considerada e reafirmada por diversos autores como fonte de informação imprescindível para a pesquisa tecnológica”. O autor ainda comenta que os bancos de patentes não são utilizados como deveria, pois não são utilizados em igualdade com outras bases de dados; chegando à conclusão que o potencial das patentes não é explorado.

Assim, esse tipo de tema torna-se relevante na área de Ciência e Tecnologia; já que busca pesquisar a questão da gestão da informação na área tecnológica e aonde estaremos buscando estudar determinado comportamento de profissionais que, segundo Bazzo (2000) são profissionais diretamente ligados ao mundo da Ciência e Tecnologia. Além disso, trabalhos semelhantes poderão ser aplicados em outras universidades, além daquelas envolvidas nessa pesquisas. 


\section{METODOLOGIA}

A pesquisa foi realizada como um estudo descritivo. A pesquisa descritiva, de acordo com Gil (1996) tem como objetivo principal, a descrição das características de determinada população ou fenômeno ou, então, o estabelecimento de relações entre variáveis.

O autor ainda aponta que algumas pesquisas descritivas vão além da simples identificação da existência de relações entre variáveis, pretendendo também determinar a natureza dessa relação.

\subsection{Universo da Pesquisa}

O universo escolhido para fazer parte desse trabalho foi composto por 586 teses e dissertações da área de engenharia química da Unicamp, que foram defendidas no período de 2000 a 2007.

Esses trabalhos que compuseram o universo estudado, estavam na sua maioria disponíveis em arquivos eletrônicos; o que possibilitou efetuar o download das mesmas através da página da Biblioteca Digital da Unicamp. Os trabalhos que não estavam disponíveis eletronicamente, tiveram o capítulo das referências fotocopiados para que pudessem fazer parte da pesquisa.

\subsection{Procedimentos Metodológicos}

Primeiramente, foi efetuada uma busca no Sistema de Bibliotecas da Unicamp (SBU) para obter os títulos das dissertações e teses defendidas no período de 2000 a 2007, da Faculdade de Engenharia Química. Com a lista em mãos, os downloads desses trabalhos puderam ser iniciados e foram salvos em pastas separadas por ano. Como já foi mencionado, os trabalhos que não estavam disponíveis na Biblioteca Digital da Unicamp, também entraram na pesquisa. 
Através das referências, ou seja, dos materiais que foram citados no texto dos trabalhos acadêmicos e referenciados posteriormente, foi feita uma contagem para verificar se a patente foi utilizada como fonte de informação. Assim, dados como: autor do trabalho, número de referências totais do trabalho, número de patentes utilizadas e os números das patentes (caso encontradas) foram sendo registradas em planilhas de acordo com o ano. Desta forma, pode-se avaliar o uso das patentes por ano e por trabalho, além da origem desses documentos utilizados. Os resultados serão mostrados a seguir através de alguns quadros e tabelas.

\section{RESULTADOS E DISCUSSÃO}

Primeiramente, vale a pena comentar sobre a cultura do depósito de patentes, assim como as diferenças que ocorrem de um país para outro. Sabe-se que no Brasil, as universidades lideram o ranking de depósitos no Instituto Nacional de Propriedade Industrial (INPI), indicando que grande parte das inovações ocorre nas universidades e não nas empresas. Segundo Silva e Dagnino (2009), nos Estados Unidos por exemplo, acontece o contrário: não é nas universidades aonde ocorre o maior número de inovações e sim nas empresas. E ao contrário do que acontece no Brasil também, as empresas americanas não buscam nas universidades o conhecimento necessário para produzir suas patentes.

Assim, seria interessante poder comparar o uso de patentes como fonte de informação numa universidade brasileira com alguma universidade americana. Pode ser que o resultado dessa comparação reflita exatamente essa diferença de cultura de inovações em universidades ou empresas. Esse tópico também será abordado na dissertação de mestrado, no qual faz parte esse artigo.

Mas voltando ao Brasil, mais especificamente para a Unicamp, nota-se através da tabela abaixo, que das 586 teses e dissertações analisadas da Unicamp, 16,4\% delas tiveram patentes citadas.

Além disso, é possível perceber alguma oscilação no que diz respeito ao número de patentes citadas de um ano para outro; mas parece haver uma tendência de crescimento do percentual de teses da Unicamp que citam patentes a partir do ano de 2004.

(c) Revista Digital de Biblioteconomia e Ciência da Informação,Campinas, v.7, n. 2, p. 219-232, jan./jun. 2010- ISSN: 1678-765X. 
Justamente a partir dessa data, a Agência de Inovação da Unicamp (INOVA) se instalou na universidade e dentre suas várias funções e tarefas, está a promoção de cursos de capacitação de trâmites para o patenteamento e da patente como fonte de informação em estudos prospectivos (UNIVERSIDADE ESTADUAL DE CAMPINAS [2007] ).

Tabela 1 - Quantidade de trabalhos acadêmicos da FEQ / Unicamp que citam patentes

\begin{tabular}{c|c|c|c}
\hline \hline Ano & $\begin{array}{c}\mathbf{N}^{\mathbf{0}} \text { Teses } \mathbf{e} \\
\text { Dissertações }\end{array}$ & $\begin{array}{c}\mathbf{N}^{\mathbf{0}} \text { Teses e } \\
\text { Dissertações que } \\
\text { citam patentes }\end{array}$ & $\mathbf{\%}$ \\
\hline \hline $\mathbf{2 0 0 0}$ & 63 & 9 & 14,3 \\
$\mathbf{2 0 0 1}$ & 86 & 8 & 9,3 \\
$\mathbf{2 0 0 2}$ & 64 & 8 & 12,5 \\
$\mathbf{2 0 0 3}$ & 85 & 13 & 15,3 \\
$\mathbf{2 0 0 4}$ & 61 & 12 & 19,7 \\
$\mathbf{2 0 0 5}$ & 75 & 19 & 25,3 \\
$\mathbf{2 0 0 6}$ & 70 & 11 & 15,7 \\
$\mathbf{2 0 0 7}$ & 82 & 16 & 19,5 \\
Total & $\mathbf{5 8 6}$ & $\mathbf{9 6}$ & $\mathbf{1 6 , 4}$ \\
\hline \hline
\end{tabular}

A Biblioteca da Área de Engenharia e Arquitetura (BAE) da Unicamp também promove cursos de capacitação semestrais para pesquisas em bases de dados de patentes, buscando fazer com que os alunos enxerguem esse documento como algo informativo e utilizável em suas pesquisas acadêmicas. Enfim, somam-se esforços para que a patente não seja lembrada somente na hora de proteger uma invenção, ou na hora de efetuar uma busca de anterioridade; mas desde o momento em que se escolha um tema para a pesquisa.

A Tabela 2 abaixo, mostra o resultado do número de patentes citadas por ano nas teses e dissertações da Unicamp. Ao analisar as planilhas elaboradas para essa pesquisa, foi possível perceber que o aluno que se utilizou da patente como fonte de informação, adquiriu esse costume pois não utilizou apenas uma patente dentre tantas outras referências e sim várias patentes. Alguns trabalhos chegaram a citar mais de 20 documentos de patentes fazendo com que elevasse o número de citações desse tipo de documento.

(c) Revista Digital de Biblioteconomia e Ciência da Informação,Campinas, v.7, n. 2, p. 219-232, jan.jjun. 2010- ISSN: 1678-765X. 
Tabela 2 - Número total de patentes citadas por ano - FEQ / Unicamp

\begin{tabular}{l|c}
\hline \hline Ano & $\mathbf{N}^{\mathbf{0}}$ de Patentes citadas / ano \\
\hline \hline $\mathbf{2 0 0 0}$ & 22 \\
$\mathbf{2 0 0 1}$ & 24 \\
$\mathbf{2 0 0 2}$ & 48 \\
$\mathbf{2 0 0 3}$ & 37 \\
$\mathbf{2 0 0 4}$ & 39 \\
$\mathbf{2 0 0 5}$ & 58 \\
$\mathbf{2 0 0 6}$ & 49 \\
$\mathbf{2 0 0 7}$ & 124 \\
Total & $\mathbf{4 0 1}$ \\
\hline \hline
\end{tabular}

Logicamente que muitos alunos ainda não vêem a patente como provedora de informações e muitas das teses e dissertações analisadas só citaram livros, artigos de congressos, artigos de periódicos, relatórios técnicos ou normas em seus trabalhos. Será que o orientador tem influência nessa questão do uso ou não uso desse tipo de documento por parte dos seus orientados? Essa é uma observação a ser pensada também e que será abordada no trabalho de dissertação.

Com os resultados das tabelas 1 e 2, pode-se então, tirar uma média do número de patentes citadas por dissertação / tese e acompanhar esses números de ano a ano, como mostra a tabela a seguir.

Tabela 3 - Média de citações de patentes por dissertações / teses

\begin{tabular}{c|c|c|c}
\hline \hline Ano & $\begin{array}{c}\mathbf{N}^{\mathbf{0}} \text { de Patentes Citadas } \\
\text { por Ano }\end{array}$ & $\begin{array}{c}\mathbf{N}^{\mathbf{0}} \text { de Dissertações e Teses } \\
\text { que Citam Patentes }\end{array}$ & $\begin{array}{c}\text { Média de Citações de } \\
\text { Patentes por Dissertações / } \\
\text { Teses }\end{array}$ \\
\hline \hline $\mathbf{2 0 0 0}$ & 22 & 9 & 2,4 \\
$\mathbf{2 0 0 1}$ & 24 & 8 & 3 \\
$\mathbf{2 0 0 2}$ & 48 & 8 & 6 \\
$\mathbf{2 0 0 3}$ & 37 & 13 & 2,8 \\
$\mathbf{2 0 0 4}$ & 39 & 12 & 3,2 \\
$\mathbf{2 0 0 5}$ & 58 & 19 & 3,1 \\
$\mathbf{2 0 0 6}$ & 49 & 11 & 4,4 \\
$\mathbf{2 0 0 7}$ & 124 & 16 & 7,7 \\
\hline \hline
\end{tabular}


Nota-se um crescimento (mais exatamente o dobro) em 2002, em comparação ao ano de 2001; mas nos anos seguintes, essa média cai. A partir do ano de 2006, pode-se observar um novo crescimento na tabela e que continua em 2007.

Essa tabela reflete o que já foi comentado na tabela 2, ou seja: alguns alunos utilizaram várias patentes em seus trabalhos (às vezes, mais do que 20), fazendo com que o número de citações desse tipo de documento por ano aumentasse, assim como a média de citações por trabalho também. Assim, pode-se observar nessa tabela, algumas oscilações da média com o passar dos anos e não um crescimento contínuo; que pode ser justificada por essa questão.

Já o Gráfico 1 abaixo, mostra a origem das patentes utilizadas e citadas nas teses e dissertações analisadas. Pode-se observar que patentes de vários países foram citadas, como: EUA, Japão, França, Inglaterra, Canadá, Alemanha, Rússia, Bélgica, entre outras. As patentes americanas foram as mais citadas $(63,8 \%)$. Porcentagens menores ficaram para as patentes japonesas (9,0\%), patentes européias (7,2\%), patentes inglesas $(4,0 \%)$, patentes alemãs (3,2\%), patentes brasileiras $(2,7 \%)$ e assim por diante. Vale a pena lembrar que na legenda desse gráfico, quando aparece o termo outras, é referente a patentes que apareceram em menor número como: patentes russas, australianas, belgas e holandesas.

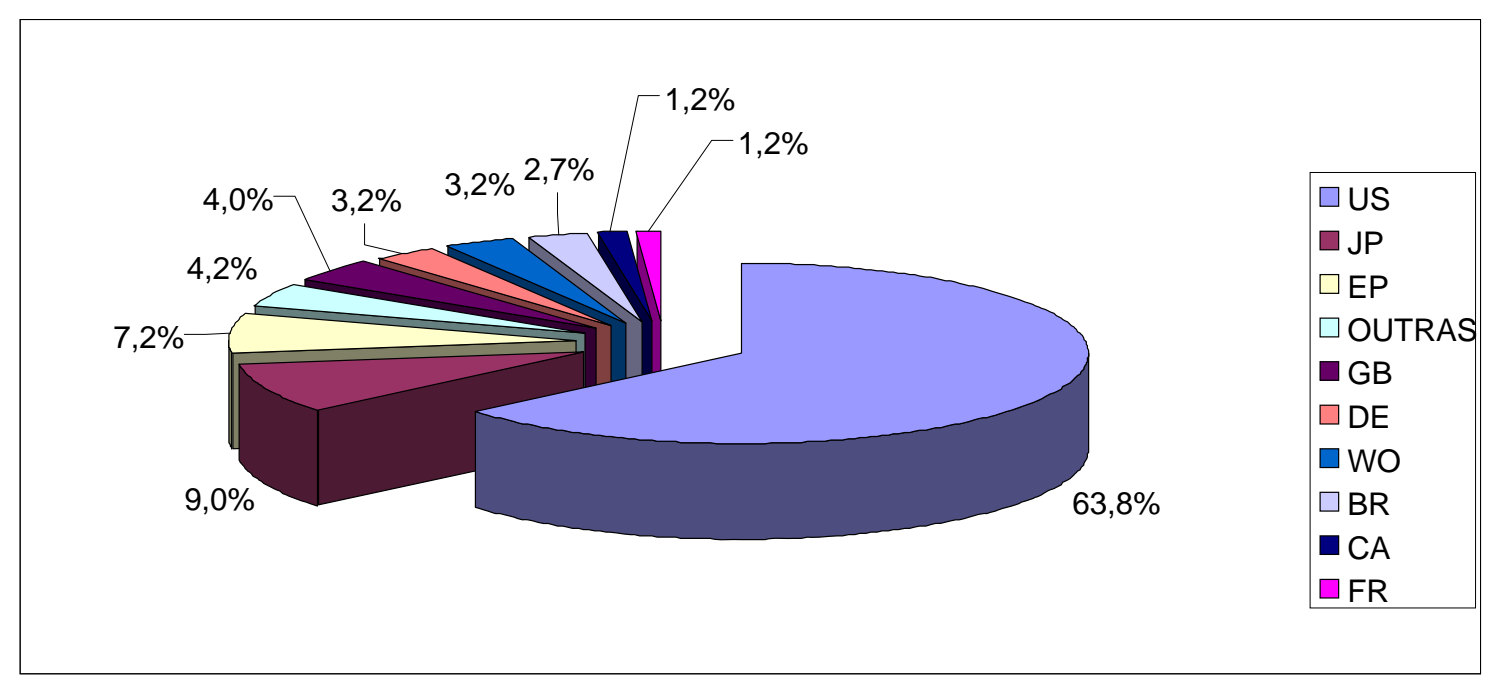

Gráfico 1 - Origem das patentes citadas - Teses e Dissertações da Unicamp

Com o resultado deste gráfico, pode-se pensar que o Brasil como um país em desenvolvimento, não tem grandes motivos para consultar suas próprias patentes quando visa desenvolver ou aperfeiçoar invenções. Por isso, os alunos consultaram e citaram 
documentos de grandes potências em números maiores. Significa um país em desenvolvimento procurando se aperfeiçoar com os países desenvolvidos.

\section{CONCLUSÕES}

Com as análises das citações bibliográficas foi possível confirmar que muitos alunos, ainda ignoram as patentes como documentos provedores de importantes informações tecnológicas para um trabalho acadêmico. Mas pode ser que com o passar do tempo, essa cultura se transforme dentro das universidades e os alunos (principalmente os da área tecnológica) passem a enxergar que a patente pode sim trazer ricas informações; ou até mais, se comparadas às outras fontes como já foi mencionado na literatura por alguns autores.

Outros documentos como livros, artigos de periódicos, artigos de congressos, teses e dissertações, normas e relatórios ainda continuam sendo os mais utilizados pelos alunos nos trabalhos acadêmicos. Talvez um trabalho conjunto de professores, biblioteca e a própria Agência de Inovação possa aumentar a visibilidade do documento de patente como um importante fornecedor da informação tecnológica no âmbito acadêmico.

Os resultados apresentados neste trabalho limitam-se à realidade da Engenharia Química da Unicamp; no entanto, outras universidades ou uma outra área de conhecimento específica, podem apresentar resultados bem diferentes dos apontados aqui.

\section{REFERÊNCIAS}

ALBUQUERQUE, E. M. Patentes e atividades inovativas: uma avaliação preliminar do caso brasileiro. In: VIOTTI, E .B.; MACEDO, M. M. (Org.). Indicadores de ciência, tecnologia e inovação no Brasil. Campinas: Unicamp, 2003. p. 329-376.

ARAÚJO, V. M. R. H. A patente como ferramenta da informação. Ciência da Informação, Brasília, v. 10, n. 2, p. 27-32, 1981.

BARROSO, W.; QUONIAM, L.; PACHECO, E. Patents as technological information in Latin América. World Patent Information, v. 31, p. 207-215, 2009.

BAZZO, W. A.; PEREIRA, L. T. V.; VON LINSIGEN, I. Educação tecnológica: enfoques para o ensino da engenharia. Florianópolis: UFSC, 2000. 173p.

BOUND, K. Brazil: the natural knowlegde economy. London: Demon, 2008. 159 p. 
FRANÇA, R. O. Patente como fonte de informação tecnológica. Perspectivas em Ciência da Informação, Belo Horizonte, v. 2, n. 2, p. 235-264, jul./dez. 1997.

GARCIA, J. C. R. Patente gera patente? Transinformação, Campinas, v. 18, n. 3, p. 213-223, set./dez. 2006.

GIL, A. C. Como elaborar projetos de pesquisa. 3. ed. São Paulo: Altlas, 1996. 159 p.

FERRAZ, M. C. C. Patentes: conceitos e princípios básicos para a recuperação da informação. São Carlos: EdUFSCar, 2006. 83 p.

MACEDO, M. F. G.; BARBOSA, A. L. F. Patentes, pesquisa \& desenvolvimento: um manual. Rio de Janeiro: Fiocruz, 2000. 161 p.

OLIVEIRA, L. G.; SUSTER, R. Informação de patentes: ferramenta indispensável para a pesquisa e o desenvolvimento tecnológico. Química Nova, São Paulo, v. 28, p. S36-S40, 2005. Suplemento.

SCHWANDER, P. Las búsquedas sobre el estado da técnica: uma obligación para las pymes innovadoras. La Haya: Oficina Europea de Patentes, 2004. Disponível em: <http://www.wipo.int/sme/es/documents/prior_art.htm>. Acesso em: 11 set. 2008.

SCHUMPETER, J.A. Teoria do desenvolvimento econômico. São Paulo: Abril Cultural, 1982. 169 p.

SILVA, R. B.; DAGNINO, R. Universidades inovam mais que empresas: é para comemorar? Jornal da Ciência, São Paulo, 23 jun. 2009. Disponível em:

<http://www.jornaldaciencia.org.br/Detalhe.jsp?id=64240 $>$. Acesso em: 21 ago. 2009.

TAVARES, P. V.; KRETZER, J.: MEDEIROS, N. Economia shumpeteriana: expoentes revolucionários e desafios endógenos da indústria brasileira. A Economia em Revista, Maringá, v. 19, p. 1-10, 2005.

UNIVERSIDADE ESTADUAL DE CAMPINAS. INOVA UNICAMP. Relatório de atividades 2006. Campinas: Inova Unicamp, [2007]. 80 p.

WALKER, R. D. Patent as scientific and technical literature. Metuchen: The Scarecrow Press, 1995. 533 p. 


\section{Juliana de Paula Ravaschio}

Mestranda do Programa de Pós-Graduação em CTS - UFSCAR. jravaschio@hotmail.com

\section{Leandro Innocentini Lopes de Faria}

Prof. Dr. do Programa de Pós-Graduação em CTS - UFSCAR. leandro@nit.ufscar.br

\section{Luc Quoniam}

Prof. Dr. do Programa de Pós-Graduação em CTS - UFSCAR. Prof. Titular da Université Du Sud Toulon Var.quoniam@univ-tln.fr

Recebido em: 31/08/2009

Aceito para publicação em: jul/2009 